\title{
A STRATEGY FOR THE RECRUITMENT OF UNDERREPRESENTED DISADVANTAGED Black StUdents to the DePaRTMENT OF Physiotherapy, University OF CAPE TOWN
}

\begin{abstract}
The lack of Black physiotherapists affects the profession, the delivery of quality service and the education of students. This project was carried out in order to reach Black scholars to inform them of the career opportunities for physiotherapists and that training opportunities are available for everyone at UCT. Thirty-one schools previously under the DET system were visited annually for 3 years by small groups of third year students in order to increase the pool of Black applicants.
\end{abstract}

Findings of the scholars' awareness of physiotherapy and the number of subsequent applications are presented. Practical problems in carrying out the visits are discussed and recommendations made for future projects of this nature.

\section{KEY WORDS: RECRUITMENT, BLACK DISADVANTAGED STUDENTS, AWARENESS OF PHYSIOTHERAPY}

\section{INTRODUCTION}

"Underrepresentation of minorities is but a subset of our continuing inability to solve our nation's racial and ethnic inequalities" (Nickens, 1992).

The composition of the physiotherapy student body of the University of Cape Town (UCT) has never reflected the geographical demography of the Western Cape and even less so that of the country.

The recruitment and retention of Black students are crucial problems in physiotherapy education. The deficiency not only has a direct bearing on the changes in the current health system, but also on the service and education of the physiotherapy profession. The lack of Black physiotherapists will also directly affect the future of the profession, the education of future students and the future delivery of quality physiotherapy practice.

With the present shift in focus to primary health care and the associated requirements of services being accessible and acceptable to the clients the necessity of having Black physiotherapists is even more essential and important to ensure that all clients receive appropriate and culturally acceptable quality management. Andrews (1992) found that lack of cultural diversity and sensitivity by health care providers resulted in poor quality care. Multiracial and multicultural socie- ties need health practitioners from divers populations who are able to introduce their own talents from their varied backgrounds (McBride 1980). This helps the clients to experience the service as being more 'user-friendly' (Nickens 1992).

Problems of underrepresentation of minority groups is a universal educational problem (Andrews 1992, Kneuppel et al 1992, Lewis 1996, Lipscombe et al 1993, Nickens 1994). In the South African context it is different in that there is an inverted demographical situation in which our "minority groups" actually form the majority of the population. Ideally, the demography of the physiotherapy profession should mirror that of the greater society (Nickens, 1994). Thus it is the very majority of the population whose increasing need for education and health services requires most urgent attention and addressing. Several authors have found that there is a tendency for graduates in health disciplines to return to their home communities to work and in turn to promote their careers (Kamien and Butterfield, 1990; Knopke et al, 1996; Kruger 1991; Rabinowitz, 1998); therefore a demographically balanced undergraduate programme will help to ensure that physiotherapy services reach all communities in South Africa: It would also serve to eliminate ethnic and racial barriers within the physiotherapy profession (Keith et al, 1985).

The issue of underrepresentation of Black students is complex and due to various factors. Historically the 'apartheid' Bantu Education Act and the Extension of University Act dictated the universities to which different races were permitted. This led to the creation of the so-called Black universities, for example, the Medical University of South Africa (MEDUNSA) and Fort Hare. The historical white universities like UCT were not permitted to admit Black students. The school education of Black scholars was administered by the Department of Education and Training (DET). The education at these schools was inferior as the classes were very large; the facilities were limited and inferior; there were insufficient teachers and they frequently were not adequately

CORRESPONDENCE:

MJ Futter

Head of Department Department of Physiotherapy University of Cape Town

Anzio Road

OBSERVATORY 7925

South Africa

Tel: (021) 406-6402 
qualified. These schools generally have a high drop-out rate which has an effect on the pool of physiotherapy applicants (Lee, 1992).

From the time the apartheid system permitted the admission of black students to UCT in 1986, the University's revision of its admission criteria for disadvantaged black students and the introduction of the Academic Development Programme in 1994 the pool of Black applicants has been very small (Table 1). This is probably due to the general population's lack of knowledge and awareness of physiotherapy as a profession as well as the lack of contact with physiotherapy services and the absence of role models with whom students can identify (Lewis, 1996). Cohen (1994) states that people are drawn to a profession by a significant personal experience that inspires them to think of a career in health care. This is very limited in the case of physiotherapy as the services are so sparsely distributed in the disadvantaged urban communities and even more so in the rural areas. Thus there is a lack of role-models with whom scholars can identify (Lewis, 1996).

Annual open-days were held in the Department of Physiotherapy, Groote Schuur Hospital to which all schools in the peninsula were invited to attend. None of the schools previously under the DET system ever attended. Reasons given were the distance from the hospital and the costs of transporting groups of scholars. This project was carried out in order to reach Black scholars to inform them of the career opportunities for physiotherapists and that training opportunities were available for everyone at UCT.

\section{AIMS}

The aims of the study were to

a) inform scholars of the admission requirements regarding their matriculation subject choice

b)increase the general population's knowledge and awareness of the scope of physiotherapy and promote it as a career.

c)increase the pool of Black applicants

\section{TARGET POPLILATION}

Thirty-one secondary and high schools previously under the DET system and in

TABLE 1: APPLICATIONS AND ADMISSION FIGURES FOR PHYSIOTHERAPY 1994-1999

\begin{tabular}{|l|l|l|l|}
\hline & APPLICATIONS & ADMISSIONS & YEAR \\
\hline TOTAL & 719 & 40 & 1999 \\
\hline Black & 261 & $3(7.5 \%)$ & \\
\hline TOTAL & 421 & 41 & 1998 \\
\hline Black & $95(22 \%)$ & $2(5 \%)$ & \\
\hline TOTAL & 534 & 39 & 1997 \\
\hline Black & $123(23 \%)$ & $4(10 \%)$ & \\
\hline TOTAL & 571 & 38 & 1996 \\
\hline Black & $125(22 \%)$ & $3(8 \%)$ & \\
\hline TOTAL & 526 & 42 & 1995 \\
\hline Black & $119(23 \%)$ & $10(24 \%)$ & \\
\hline TOTAL & 542 & 40 & 1994 \\
\hline Black & $119(23 \%)$ & $4(10 \%)$ & \\
\hline
\end{tabular}

\section{TABLE 2: QUESTIONS ASKED PRIOR TO PRESENTATION}

Who knows what physiotherapy is?

Who has been for physiotherapy before?

For what?

Did it help?

Who has had a family member go for physiotherapy treatment?

For what?

What sort of treatment did they receive?

Did it help?

How many of you are considering applying for physiotherapy?

the Cape Town area were identified through the Schools Liaison Officer at UCT. None of these had previously attended the open-days due to the transport constraints mentioned above.

Teachers, career guidance officers and scholars from grades 9 to 12 were invited to attend. This was to stimulate an interest in physiotherapy as a possible career choice for the matriculants and grade 11 scholars. It was also deemed important to reach the grades 8,9 and 10 scholars, not only to increase their knowledge of the scope of physiotherapy, but also to ensure that they made the correct subject choices for matriculation should they be interested in following physiotherapy as a career.

\section{METHODOLOGY}

During the third year of the undergraduate programme physiotherapy students were required to do a project in the community as a requirement for the Community Physiotherapy course. During 1996, 1997 and 1998 these students were placed into groups of 4 or fewer and each group was allocated 3 schools to visit. The aims and the methods of approaching the project were discussed with them. They were supplied with the addresses and telephone numbers of the specific schools which they were to visit. Kneuppel et al (1992) found that the most effective way of expanding the applicant pool and recruiting students is to provide personal contact between scholars and young people in the profession.

Students contacted the schools allocated to them and made arrangements with the career guidance teacher or the principal regarding suitable days and times for the visits to take place.

A variety of visual displays of the scope of physiotherapy were made by 
the students. Some groups made posters, others made slides and one group made a video. The University's pamphlets on the scope of physiotherapy, admission requirements, course contents, tuition fees, salaries and career opportunities were obtained from the Career's Office for distribution. The contents of the verbal presentation included aspects of financial assistance that the University provides for disadvantaged students and the Academic Development Programme which allows the four-year course to be spread over five years.

Posters advertising the visits were placed in the schools on the scholars' noticeboards approximately a week before the meeting.

At the beginning of each presentation scholars were asked a number of questions in order to establish their level of understanding and awareness of physiotherapy. These are shown in Table 2.

Balance balls, crutches, tripods, wobble boards, peak expiratory flow meters and stethoscopes were taken for specific demonstrations that were to be given.

Some of the demonstrations were given with the scholars as models, but where possible actual clients were used. This was followed by a display of colourful photographs, posters, slides or video of clients suffering from a variety of medical conditions and being treated in different clinical settings in order to convey the full spectrum of preventative, promotive, curative and rehabilitation aspects of physiotherapy. Detailed commentary was provided and scholars and teachers were encouraged to ask questions during the presentations.

The presentations were given for 20 minutes. This was followed by $10 \mathrm{~min}-$ utes for questions and explanations.

Leaflets were left with the career guidance teachers for distribution during the year.

\section{FINDINGS AND DISCUSSION}

By asking questions before the presentation it was found that the scholars knew very little about physiotherapy. The percentage of scholars that knew something about physiotherapy at the beginning of the presentations are reflected in Table 3. The schools where the percentages were higher were the schools situated in the higher economic residential areas where the parents had a higher level of education. These schools were also situated closer to health care facilities than the lower income areas. Otherwise these percentages have no significance as it appears that the schools arranged for different classes to attend the presentations each year. Hence it does not appear as though the number of scholars who knew anything about physiotherapy increased from year to year.

In general the teachers were unaware of the scope of physiotherapy. Some of the career guidance teachers became very keen about having something other than medicine and nursing presented to the students and requested that the schools be visited annually. They were also pleased to know that their promising students had a choice of careers rather than thinking of medicine as the only option.

Scholars were less attentive when the presentations were made during their lunch breaks or after school. The best time for gaining their cooperation and interest was after the short tea break.

Generally the scholars were very interested in the presentations and participated maximally in the demonstrations. However, in the schools where there were scholars present from grades 8 and 9 they were less responsive and there were more disruptions during the demonstrations. It appeared as though they were not yet serious about giving much thought to their future careers. The grade 11 and 12 scholars asked more serious questions and often requested application forms which were interpreted as encouraging signs.

TABLE 3: APPROXIMATE PERCENTAGE OF SCHOLARS THAT KNEW SOMETHING ABOUT PHYSIOTHERAPY

\begin{tabular}{|c|c|c|c|c|c|c|c|c|c|c|c|}
\hline SCHOOL & 1 & 2 & 3 & 4 & 5 & 6 & 7 & 8 & 9 & 10 & 11 \\
\hline 1996 & $10 \%$ & $0 \%$ & $10 \%$ & $6 \%$ & $16 \%$ & $3 \%$ & $7 \%$ & $9 \%$ & $13 \%$ & $11 \%$ & $0 \%$ \\
\hline 1997 & $9 \%$ & $2 \%$ & $9 \%$ & $5 \%$ & $18 \%$ & $0 \%$ & $10 \%$ & $9 \%$ & $10 \%$ & $12 \%$ & $1 \%$ \\
\hline 1998 & $11 \%$ & $3 \%$ & $10 \%$ & $8 \%$ & $15 \%$ & $4 \%$ & $9 \%$ & $8 \%$ & $12 \%$ & $14 \%$ & $1 \%$ \\
\hline SCHOOL & 12 & 13 & 14 & 15 & 16 & 17 & 18 & 19 & 20 & 21 & 22 \\
\hline 1996 & $0 \%$ & $18 \%$ & $4 \%$ & $2 \%$ & $3 \%$ & $13 \%$ & $8 \%$ & $1 \%$ & $3 \%$ & $7 \%$ & $6 \%$ \\
\hline 1997 & $1 \%$ & $11 \%$ & $4 \%$ & $0 \%$ & $1 \%$ & $15 \%$ & $6 \%$ & $1 \%$ & $2 \%$ & $8 \%$ & $5 \%$ \\
\hline 1998 & $0 \%$ & $15 \%$ & $6 \%$ & $2 \%$ & $0 \%$ & $14 \%$ & $7 \%$ & $1 \%$ & $2 \%$ & $7 \%$ & $8 \%$ \\
\hline SCHOOL & 23 & 24 & 25 & 26 & 27 & 28 & 29 & 30 & 31 & & \\
\hline 1996 & $3 \%$ & $2 \%$ & $56 \%$ & $10 \%$ & $21 \%$ & $5 \%$ & $7 \%$ & $11 \%$ & $10 \%$ & & \\
\hline 1997 & $1 \%$ & $0 \%$ & $53 \%$ & $8 \%$ & $19 \%$ & $6 \%$ & $8 \%$ & $10 \%$ & $13 \%$ & & \\
\hline 1998 & $2 \%$ & $1 \%$ & $50 \%$ & $9 \%$ & $20 \%$ & $4 \%$ & $7 \%$ & $11 \%$ & $9 \%$ & & \\
\hline
\end{tabular}


The scholars had difficulty comprehending English. The students had to speak slowly and clearly in order for them to understand the presentations. In a few groups where there were Xhosa speaking students they addressed the scholars in their home tongue and this was extremely well accepted. This finding is supported by Dowell's (1996) study where Black student recruiters were found to be more appealing compared to the white students. Dowell (1996), McBride (1980) and Yergan et al (1988) also found the use of Black role models to be advantageous in recruiting Black scholars.

Some groups were obliged to use the principals or guidance teachers as interpreters to ensure that the scholars understood what was being said.

Many scholars voiced the opinion that they would not be able to study physiotherapy as it involved science and they perceived that they simply did not have the potential to cope with it at tertiary level. Other scholars had dropped physical science in grade 9 or 10 as they had struggled so much with the subject.

After the preliminary questions regarding the scope of physiotherapy or questions regarding the health problems of their own family members the scholars asked the following questions in the order that they are listed below:

a. How much does a physiotherapist earn?

b. Are there many jobs for physiotherapists?

c. How long is the course?

$\mathrm{d}$. What are the tuition fees?

e. At which universities can physiotherapy be studied?

When these questions had been answered they immediately asked how much doctors earn. The poor salaries of physiotherapists and recent media coverage of the lack of job opportunities in Cape Town had an immediate dampening effect on their original enthusiasm. They also perceived that it would be impossible to even think of applying to UCT as they had the preconception that their marks simply would not be competitive enough for admission. They also raised the issue that UCT was the most expensive University in South Africa and totally out of reach to them.
The physiotherapy students expressed the view that for the first time they had been exposed to the living environment of many of the clients with whom they had been dealing during their clinical rotations. This is understandable as the community projects are done early in the year and very few of the students would have already been exposed to a clinical rotation in the community by that time. They felt that the visits had helped them to be able to relate to their clients environment more easily and that this would help to make their home advice more appropriate.

To date there have been no applications for physiotherapy from any of the 31 historically Black schools visited over the 3-year period. This is in spite of the University's vigorous efforts at transformation and increased financial aid to disadvantaged students in order to achieve a student body which reflects the demographics of the country. Although the Black student body throughout the University has increased this has not been the case in the physiotherapy programme.

\section{PROBLEMS}

1.It was often very difficult to make telephonic contact with the schools. Sometimes the telephone rang unanswered for days at a time or it would be permanently engaged in spite of confirming with the telephone operator that the lines were functioning and the telephones were in order. In other situations the telephone calls were never returned.

2. Locating the schools was not easy as many of the street names were not listed on the city map and many streets had no name signs.

3. Lack of sound equipment meant that with large groups not all the scholars could hear what was being said.

4. Some schools did not have electricity. They all had electricity laid on, but many had had the service discontinued as their bills had not been paid. Thus in spite of being reassured that there were facilities for the slide or video show on arrival it was not functioning and the presentations had to be altered.

5. Schools that did have functioning electricity, screens, overhead projectors and slide projectors sometimes did not have curtains to darken the room and so the visibility was again unsatisfactory.

6. Appointments were not kept by the school liaison person. Sometimes this was for no apparent reason, but other times was due to strikes when the teachers did not turn up for work and the pupils were left to their own devices.

7.The venues were inadequate. Apart from the lighting and electricity most venues were too small and cramped making it difficult for the pupils to concentrate.

\section{CONCLUSION}

This project was set up to increase the pool of Black physiotherapy applicants by means of increasing the awareness of physiotherapy as a profession and informing prospective applicants timeously of the correct subject choice for admission to the course.

Even though there have been no applications from any of the 31 disadvantaged schools visited the project should not be seen as a once off study, but should be conducted over a period of at least 5 years before a true reflection of its impact can be made. Scholars from grades 10,11 and 12 may have become interested in following physiotherapy as a career, but may not have had the correct subject choice.

Scholars from the lower grades may still apply in the future as a result of the presentations and their increased awareness of physiotherapy as a profession. Kneuppel et al (1992) maintained that increasing the possible student pool is a long-term endeavour and that the personal contact with the students and professionals assists in the recruitment process.

It is clear from this project that the majority of pupils had not considered applying for the physiotherapy course because they were not aware of physiotherapy as a career option. This is an aspect that the profession as a whole needs to address.

Although empirical deductions cannot be made from a small-scale project such as this, it may be speculated that an underlying lack of knowledge about the profession is indeed widespread throughout the former DET schools. 


\section{RECOMMENDATIONS}

1. A Xhosa speaking teacher should be present who will translate and clarify any misunderstandings.

2. It is advisable to take one's own audio-visual equipment for the presentations and to ensure that the venue has adequate facilities for making the room sufficiently dark.

3. Demonstrations that involve patients should be used whenever possible as they were found to be the most appealing aspect of the presentations. Where this was not possible visual aids used like slides and photographs of actual clients were found to be the next best way of maintaining the scholars' interest.

4. More than one visit should be made to each school to make class sizes manageable and ensure the clarity of the content of the presentation. Small rooms with fewer than 40 pupils make the presentation more personal and give the scholars more opportunity to ask questions.

5. Teachers should be encouraged to attend so that they can help to pass on the information to future scholars.

6 . Introductions by the teachers helped to stimulate an interest in the topic. In schools where this was not provided the scholars tended to be noisy and not very attentive.

\section{REFERENCES:}

Andrews M 1992 Cultural perspectives on nursing in the $21^{\text {st }}$ century. In: Dowell M. 1996 Issues in Recruitment and Retention of Minority Nursing Students. Journal of Nursing Education 35(7):293-297

Cohen JJ. 1994 From the President: Project 3000 by 2000 and Health Care Reform. Academic Medicine 69(9):728

Dowell M. 1996 Issues in Recruitment and Retention of Minority Nursing Students. Journal of Nursing Education 35(7):293-297

Kamien M and Butterfield H1. 1990 Some solutions to the shortage of general practitioners in rural Australia. Medical Journal of Australia 153:105-107

Keith S. 1985 Effects of Affirmative Action in Medical Schools. New England Journal of Medicine 313(24):1519-1524

Kneuppel K \& Szczotka L. 1992 How can optometry become more effective in recruiting and retaining appropriate numbers of underrepresented and disadvantaged students. Journal of the American Optometric Association 63(11):802-804

Knopke IH, Northrup RS and Hartman JA. 1986 BioPre. A premedical program for rural high school students. Journal of the American Medical Association 256:2548-2451

Kruger FJ 1991 Education and training: Career opportunities for the 1990's. Enterprise: Networking for Africa's entrepreneurs and leaders $39: 25$

Lee MC. 1992 'Programming' Minorities for Medicine. Journal of the American Medical Association 267(17):2391,2394-2395
Lewis CL. 1996 A State University's Model Program to increase the number of its Disadvantaged students who matriculate into Health Professions schools. American Medicine 71(10):1050-1057

Lipscomb WD, Mullan PB, Zepeda M, Price J. 1993 Enhancing Minority Representation at Medical School. Academic Medicine 68(10):510-512

McBride ET. 1980 Increasing Minorities in the Physical Therapy Profession through Student Admission. Journal of Physical Therapy $60(10): 1284-1288$

Nickens HW. 1992 The rationale for minority-targeted programs in medicine in the 1990's. Journal of the American Medical Association 267(17):2390-5

Nickens HW, Ready TP, Petersdorf RG. 1994 Project 3000 by 2000 and healthcare reform. New England Journal of Medicine 331(7):472476

Yergan J, Phillips TJ, Schaad DC, May, A, Drickey R, Yerby MS. 1988 Medical Education for Minorities at a US Medical School. Journal of Medical Education 22(4):317-324

\section{Your Best Connection} in the UK

As the UK's second fastest growing Recruitment Agency, it is not surprising that we are able to offer long term contracts to physiotherapists in every hospital and private practice throughout the UK. We offer..

\section{- Superb rates of pay and bonuses}

- CPSM membership refund

- Accommodation arranged

- Friendly and helpful advice

- Wide range of jobs to choose from

Call Johannesburg 0118815443 and speak to Brenda, our SA Co-ordinator.

PO Box 785553

Sandton 2146

email: bbt@mweb.com.za

$\mathbf{B} \cdot \mathbf{B} \cdot \mathbf{T}$

Medical

\section{London Leeds Bristol Birmingham}

